\title{
RESEARCH ON DECISION MAKINg REgaRdiNg IN DATING EVENTS FOR UNMARRIED FEMALE JUNIOR HIGH SCHOOL TEACHERS
}

\author{
Han-Chen Huang ${ }^{1}$, Cheng-I Hou ${ }^{1 *}$ and Yu-Hsuan Tseng ${ }^{2}$ \\ ${ }^{1}$ Department of Tourism and M.I.C.E., Chung Hua University, Taiwan \\ ${ }^{2}$ GuangWu Junior High School, Taiwan
}

\begin{abstract}
This study intends to investigate the mate selection criteria and weights of unmarried female junior high school teachers in Taiwan. This study used the Delphi method to clarify mate selection criteria. The primary assessment criteria included 4 items: social condition, personal condition, emotional condition, and family background. The secondary assessment criteria included 24 items. This study used AHP to determine that, among the primary assessment criteria, the order of importance is, as follows: emotional condition, personal condition, social condition, and family background. Among the secondary assessment criteria, the order of importance of the top 10 is, as follows: carefulness and meticulousness, tenderness and thoughtfulness, sense of safety, parents are alive and healthy, health status, conviction record, birth order, monthly income, sense of humor, and value.
\end{abstract}

\section{KEYWORDS}

Delphi method, Analytic Hierarchy Process, Mate Selection.

\section{INTRODUCTION}

Will modern women in Taiwan choose not to get married due to high self-awareness? Actually, their desire for marriage is beyond the imagination of general people. However, reality is cruel: with increased age, it is increasingly difficult for women with higher income and educational level to find the ideal spouse to marry.

Society is unbalanced, meaning there are unequal opportunities for men and women. The traditional concept of mate selection criteria still shackles the Taiwanese, and it is very difficult for women with high educational level, high income, and older age to find a man with equal age and socioeconomic status to marry. Observations of the majority of single men in Taiwan showed that, the socioeconomic status of most single men is the lowest. Therefore, the majority of single men cannot match mature and sophisticated women with "three highs." While they can marry foreign spouses; unmarried mature and sophisticated women have no choice but to remain unmarried [1].

In Taiwan, the work environment and salary of female junior high school teachers are admirable, and they can even enjoy winter and summer vacations. Therefore, their occupation is the ideal occupation for a spouse, as seen from the perspective of many single men. The educational level of teachers is high, and their income is stable. Due to the limited and narrow work environments, it is increasingly difficult for unmarried female teachers to choose a spouse. However, unmarried teachers still intend to get married. Unfortunately, increasing school workloads have decreased their opportunity to get to know men in other workplaces. Moreover, their living circle is 
restricted to school, and most of their friends are teachers. Such an environment directly affects unmarried female teachers' mate selection [2].

According to a survey of the Department of Household Registration, Ministry of the Interior, Taiwan [3], in recent years, and the number of people getting married has decreased significantly, while the age at first marriage has gradually increased. Female age at first marriage was 29.5, which is increased by 2.7, as compared with that of 10 years ago [3]. The 2009 idol drama "My Queen" described the process; where the female leading character over the age of 30 focused on her career achievements, and only made changes after she met a man, who was younger than her by 8 years, in order to pursue happiness. After the debut of this idol drama, people in Taiwan noticed that there are the so-called "underdogs" in real life [4], even though they may have great career achievements. One group of such underdogs is unmarried female junior high school teachers. Teachers in Taiwan, especially junior high school teachers, still have to bear academic pressure. Although 12-year compulsory education has been implemented, the workload of junior high schools has been increased, leading to decreased leisure entertainment for junior high school teachers after work, as they spend most of their time on dealing with school issues. Similar to students, junior high school teachers arrive at school at approximately 7 a.m., and spend all day teaching, dealing with school affairs, student issues, communicating with parents, and participating in seminars. After a busy day, they usually leave school between6and 7 p.m. and go home to rest after dinner. In addition, they still have to participate in school activities and seminars on most weekends. Therefore, from Monday to Sunday, as they almost have no time to rest, how can they have the energy and time to get to know single unmarried men?

In order to enable currently single unmarried female teachers to get married as soon as possible, this study intends to help them understand their mate selection criteria, how to preliminarily screen dates, and further observe and become familiar with them in order to shorten the dating process within a mutual adjustment period to successfully wed.

\section{LITERATURE REVIEW}

\subsection{MAte SELECTION}

The foundation of a happy marriage is laid on the process of mate selection [5]. The Chinese dictionary, as compiled by the Ministry of Education, explains that "mate selection" refers to the process where a person selects a person of the opposite sex to marry [6]. The behavior of selection occurs, followed by competition, elimination, and screening of criteria. Mate selection is a social exchange behavior $[7,8]$, where a person uses their congenital external conditions to attract a person of the opposite sex, and then, exhibit their best side in front of the other. In addition to competition, individuals must also have to flexibly apply psychological strategies in front of competitors of the same gender in order to wed $[9,10]$. However, due to the influence of traditional concepts and atmosphere, the early mate selection models of the Taiwanese included matchmaking and blind dates. The use of these two methods was usually determined by parents, or the elderly with high status in the family, and the factors of consideration were mainly family background, economic condition, and benefit exchange between the two families [11]. Thus, an individual's life partner was determined by other people. At the time, mate selection was mainly dependent upon two families, and personal affection and preference were regarded as a behavior of betrayal against family [12].

\subsection{Mate Selection Criteria}

How to select a partner who meets the self-expectations of many people? Mate selection is dependent upon careful assessment, getting along well for a long time, and mutual adjustment. 
There are many factors affecting mate selection, but can generally be divided into age, gender, educational level, family background, and socioeconomic status. Such factors can be further subdivided into appearance, height, weight, income, family background, personality, interpersonal relationship, occupation, interest, value, and religious belief [13-15]. Mate selection is the compliance of individual behaviors with the principles of "rational selection" and "multiple indicators," as well as the "continuous search" and "picking and choosing" of candidates in order to screen several people to find the ideal partner [16]. Since individuals must pick and choose, what are the criteria? Where to start? Ordinary people will make choices according to similarity and complementarity $[17,18]$ :

I. Similarity: Individuals suggest that the two people must share similar personalities, interests, and ambitions, as similarity can avoid conflict.

II. Complementarity: Individuals suggest that the two people must balance and complement each other, and share with each other completely different living experiences in order to contribute to better mutual development.

The studies by Chu [19] and Lin [20] found that the factors affecting the phenomenon of unmarried female junior high school teachers are, as follows:

I. Excessively high educational level and long-term education lead to spending excessive amount of time obtaining a high degree.

II. Work environment affects the opportunity of mate selection. In school environments, there are more female teachers and fewer male teachers (unbalanced ratio), leading to a significant decrease in opportunities to get to know people of the opposite sex.

III. The general public view teachers' morality and private life from a higher standard, which relatively affects female teachers' scope of mate selection.

\section{RESEARCH METHOD}

This study used literature analysis to analyze the factors affecting mate selection, and then applied the Delphi method in order to obtain the assessment criteria of mate selection criteria. Finally, this study used the Analytic Hierarchy Process to calculate the weights of the various assessment criteria of mate selection criteria. The Delphi method is an expert prediction approach, as well as a group decision decision-making method, and its main purpose is to obtain the consensus of experts receiving interviews and seek consistent opinions of the research subjects. This method collects a variety of ideas, and considers experts' independent determination of quality. The Analytical Hierarchy Process (AHP) is a theory proposed by Thomas L. Saaty at the University of Pittsburgh in the U.S. in 1971. The theory of AHP became more complete after 1980 [21, 22].

It is a decision-making method that mainly solves complicated decision-making problems that have major impact on decision-makers. Under an uncertain situation, a decision is made according to several assessment criteria. The hierarchical structure is beneficial to understanding issues and dividing complicated and non-structured situations into several components or integers. Moreover, as the order of the hierarchy is set, every variable is endowed with a value according to the subjective determination of importance. After a series of judgments and statistics, the priority of every variable is determined to in order facilitate decision-makers considerations and reach conclusions $[23,24]$.

This study enrolled 8 female junior high school teachers in Hsinchu as the subjects to complete the Delphi questionnaire. After consistent results were obtained from 3 rounds of questionnaire surveys, the hierarchical structure of the key factors affecting mate selection criteria of unmarried female junior high school teachers is as shown in Figure 1. 
International Journal of Computer Science \& Information Technology (IJCSIT) Vol 9, No 1, February 2017

A 9-point scale was applied to the assessment of the AHP questionnaire, according to the suggestion of Saaty [24]. Therefore, importance was measured using the scores of 1, 3, 5, 7, and 9, while factors whose importance was between two scores were measured using the scores of 2, 4, 6 , and 8. This study conducted an AHP questionnaire survey on 25 unmarried female junior high school teachers aged 25-35 in Hsinchu.

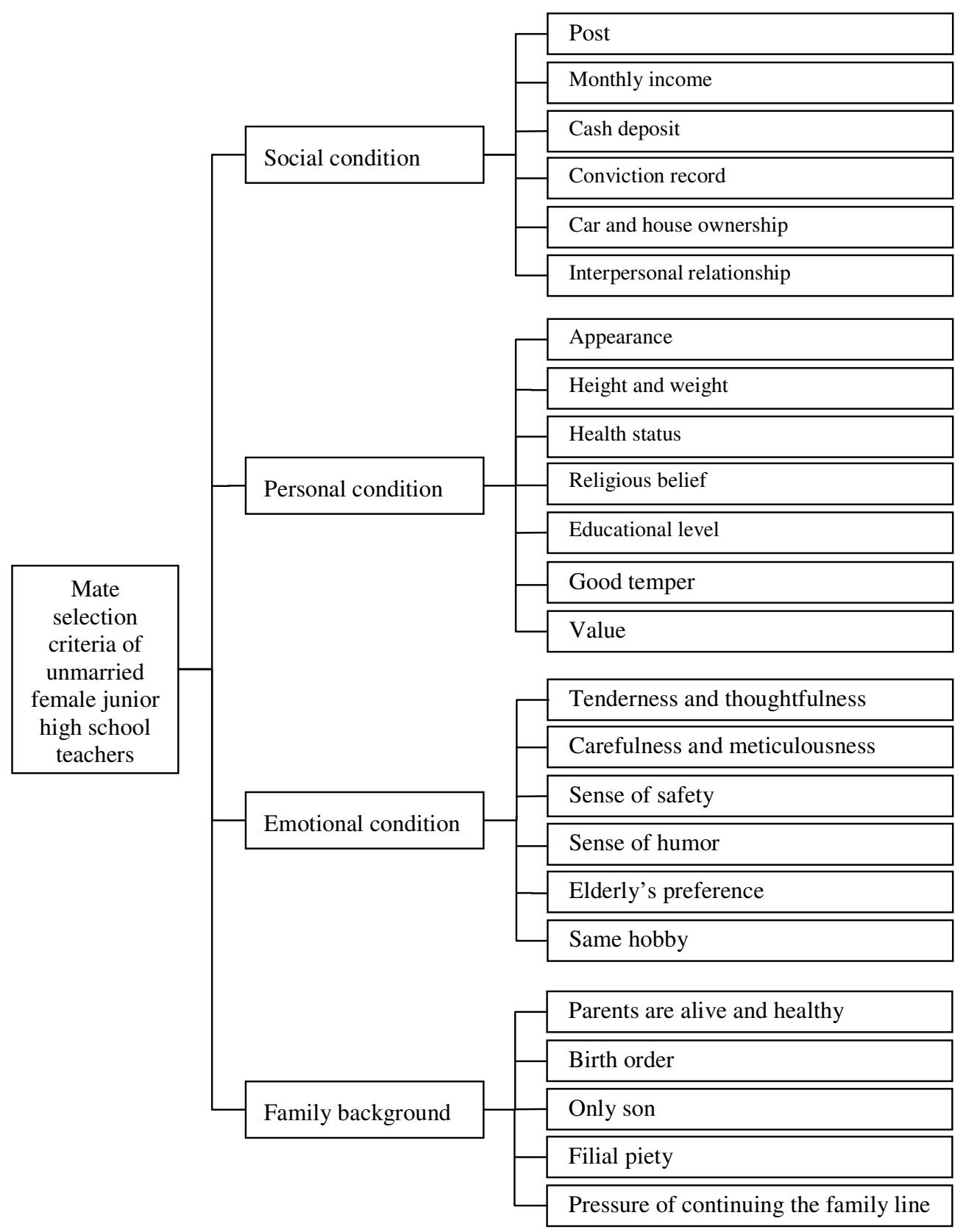

Figure 1. Hierarchical Structure of Mate Selection Criteria of Unmarried Female Junior High School Teachers 


\section{RESULTS AND DISCUSSION}

This study used AHP to investigate the importance of mate selection criteria of unmarried female junior high school teachers. During the pairwise assessment of AHP, the transitivity of the pros, cons, and strength relationships must be satisfied. However, during the actual process, deviations caused by some factors are inevitable, thus, consistency testing is required. Satty [24] suggested the use of Consistence Index (C.I.) and Consistence Ratio (C.R.) to perform consistency testing of the pairwise comparison matrix. The results of the pairwise comparison matrix are as shown in Table 1. The weights and order of importance of mate selection criteria are as shown in Table 2.

Table 1. Consistency Test

\begin{tabular}{|c|c|c|c|c|}
\hline \multicolumn{2}{|c|}{ Criteria } & C.I. & C.R. & Result of consistency test \\
\hline \multicolumn{2}{|c|}{ Hierarchy of primary assessment criteria } & 0.072 & 0.080 & Passed \\
\hline \multirow{2}{*}{$\begin{array}{c}\text { Hierarchy of } \\
\text { secondary } \\
\text { assessment criteria }\end{array}$} & Social condition & 0.096 & 0.078 & Passed \\
\cline { 2 - 5 } & Personal condition & 0.062 & 0.047 & Passed \\
\cline { 2 - 5 } & Emotional condition & 0.061 & 0.049 & Passed \\
\cline { 2 - 5 } & Family background & 0.036 & 0.032 & Passed \\
\hline
\end{tabular}

Table 2. Weights and Order of Importance

\begin{tabular}{|c|c|c|c|c|c|c|}
\hline Goal & $\begin{array}{c}\text { Primary } \\
\text { assessment } \\
\text { criteria }\end{array}$ & Weight & Order & $\begin{array}{c}\text { Secondary } \\
\text { assessment criteria }\end{array}$ & $\begin{array}{c}\text { Hierarchical } \\
\text { weight }\end{array}$ & $\begin{array}{c}\text { Hierarchical } \\
\text { order }\end{array}$ \\
\hline \multirow{22}{*}{$\begin{array}{l}\text { Mate selection } \\
\text { criteria of } \\
\text { unmarried } \\
\text { female junior } \\
\text { high school } \\
\text { teachers }\end{array}$} & \multirow{6}{*}{$\begin{array}{l}\text { Social } \\
\text { condition }\end{array}$} & \multirow{6}{*}{0.208} & \multirow{6}{*}{3} & Post & 0.143 & 3 \\
\hline & & & & Monthly income & 0.247 & 2 \\
\hline & & & & Cash deposit & 0.134 & 4 \\
\hline & & & & Conviction record & 0.290 & 1 \\
\hline & & & & $\begin{array}{c}\text { Car and house } \\
\text { ownership }\end{array}$ & 0.089 & 6 \\
\hline & & & & $\begin{array}{l}\text { Interpersonal } \\
\text { relationship }\end{array}$ & 0.094 & 5 \\
\hline & \multirow{7}{*}{$\begin{array}{l}\text { Personal } \\
\text { condition }\end{array}$} & \multirow{7}{*}{0.248} & \multirow{7}{*}{2} & Appearance & 0.147 & 3 \\
\hline & & & & Height and weight & 0.127 & 5 \\
\hline & & & & Health status & 0.247 & 1 \\
\hline & & & & Religious belief & 0.059 & 7 \\
\hline & & & & Educational level & 0.114 & 6 \\
\hline & & & & Good temper & 0.138 & 4 \\
\hline & & & & Value & 0.165 & 2 \\
\hline & \multirow{6}{*}{$\begin{array}{l}\text { Emotional } \\
\text { condition }\end{array}$} & \multirow{6}{*}{0.342} & \multirow{6}{*}{1} & $\begin{array}{l}\text { Tenderness and } \\
\text { thoughtfulness }\end{array}$ & 0.239 & 2 \\
\hline & & & & $\begin{array}{l}\text { Carefulness and } \\
\text { meticulousness }\end{array}$ & 0.241 & 1 \\
\hline & & & & Sense of safety & 0.216 & 3 \\
\hline & & & & Sense of humor & 0.124 & 4 \\
\hline & & & & Elderly's preference & 0.082 & 6 \\
\hline & & & & Same hobby & 0.094 & 5 \\
\hline & \multirow{3}{*}{$\begin{array}{c}\text { Family } \\
\text { background }\end{array}$} & \multirow{3}{*}{0.203} & \multirow{3}{*}{4} & $\begin{array}{c}\text { Parents are alive } \\
\text { and healthy }\end{array}$ & 0.312 & 1 \\
\hline & & & & Birth order & 0.280 & 2 \\
\hline & & & & Only son & 0.127 & 5 \\
\hline
\end{tabular}




\begin{tabular}{|l|l|l|l|l|l|l|}
\hline & & & Filial piety & 0.140 & 3 \\
\cline { 4 - 5 } & & $\begin{array}{c}\text { Pressure of } \\
\text { continuing the } \\
\text { family line }\end{array}$ & 0.138 & 4 \\
\hline
\end{tabular}

\subsection{Weights And Order Of Primary AsSessment Criteria}

The primary assessment criteria included 4 major dimensions, and their C.I. $=0.072$ and C.R. $=0.080$ values were $<0.1$, as recommended by Saaty. The pairwise comparison and hierarchical calculation showed that the order of importance was as follows: emotional condition (0.354), personal condition (0.244), family background (0.205), and social condition (0.198).

\subsection{Weights AND ORder OF SECONDARY ASSESSMENT CRiteria}

I. Social condition

This assessment criterion included six items, and their C.I. $=0.096$ and C.R. $=0.078$ values were $<0.1$, as recommended by Saaty. The pairwise comparison and hierarchical calculation showed that the order of importance was as follows: conviction record (0.290), monthly income (0.247), post (0.143), cash deposit $(0.134)$, interpersonal relationship (0.094), and car and house ownership (0.089).

\section{Personal condition}

This assessment criterion included seven items, and their C.I. $=0.062$ and C.R. $=0.047$ values were $<0.1$, as recommended by Saaty. The pairwise comparison and hierarchical calculation showed that the order of importance was as follows: health status (0.247), value (0.165), appearance (0.147), good temper (0.138), height and weight (0.127), educational level (0.114), and religious belief $(0.059)$.

III. Emotional condition

This assessment criterion included six items, and their C.I. $=0.061$ and C.R. $=0.049$ values were $<0.1$, as recommended by Saaty. The pairwise comparison and hierarchical calculation showed that the order of importance was as follows: carefulness and meticulousness (0.241), tenderness and thoughtfulness (0.239), sense of safety (0.216), sense of humor $(0.124)$, same hobby $(0.094)$, and elderly preference (0.082).

IV. Family background

This assessment criterion included five items, and their C.I. $=0.036$ and C.R. $=0.032$ values were $<0.1$, as recommended by Saaty. The pairwise comparison and hierarchical calculation showed that the order of importance wasas follows: parents are alive and healthy (0.312), birth order (0.280), filial piety (0.140), pressure of continuing the family line (0.138), and only son (0.127).

\subsection{OVERALl WEIGHT AND ORDER}

The overall weight is as shown in Table 3. After hierarchical analysis and calculation of 24 items of the secondary assessment criteria, the overall weight and order were obtained. The order of importance of the top 10 was as follows: carefulness and meticulousness $(0.083)$, tenderness and 
thoughtfulness (0.082), sense of safety (0.074), parents are alive and healthy (0.063), health status $(0.061)$, conviction record $(0.060)$, birth order $(0.057)$, monthly income $(0.051)$, sense of humor (0.042), and value (0.040). As shown in Table 3, during the mate selection of unmarried female teachers, the most important dimension was emotional condition - carefulness and meticulousness, tenderness and thoughtfulness, and provision of sense of safety were most important in emotional condition, followed by health status in personal condition. Regardless how great the bond or outstanding various conditions, a couple cannot spend their life with each other if there is no healthy body. In terms of social conditions, because teachers' work is constrained by high moral standards, conviction record was certainly the most important screening criterion. In terms of family background, parents are alive and healthy was most important, as many family issues most difficult to adapt to are derived from this item. How an unmarried female teacher reaches a balance between work and getting along with parents-in-law becomes a key factor.

Due to the stability of work and change of social environment, the mate selection criteria of unmarried female teachers are different from those of the stereotype. However, analysis of various criteria enables them to better understand the "Mr. Right" that they intend to pick and choose, which can assist unmarried female teachers in reducing screening time and number of candidates, and choose a man that is most suitable for them according to their needs during mate selection.

Table 3. Order of Mate Selection Criteria of Unmarried Female Junior High School Teachers

\begin{tabular}{|c|c|c|}
\hline Hierarchical assessment criteria & Overall weight & Overall order \\
\hline Carefulness and meticulousness & $8.26 \%$ & 1 \\
\hline Tenderness and thoughtfulness & $8.21 \%$ & 2 \\
\hline Sense of safety & $7.42 \%$ & 3 \\
\hline Parents are alive and healthy & $6.35 \%$ & 4 \\
\hline Health status & $6.14 \%$ & 5 \\
\hline Conviction record & $6.05 \%$ & 6 \\
\hline Birth order & $5.70 \%$ & 7 \\
\hline Monthly income & $5.14 \%$ & 8 \\
\hline Sense of humor & $4.26 \%$ & 9 \\
\hline Value & $4.10 \%$ & 10 \\
\hline Appearance & $3.67 \%$ & 11 \\
\hline Good temper & $3.44 \%$ & 12 \\
\hline Same hobby & $3.23 \%$ & 13 \\
\hline Height and weight & $3.15 \%$ & 14 \\
\hline Post & $2.99 \%$ & 15 \\
\hline Filial piety & $2.85 \%$ & 16 \\
\hline Educational level & $2.83 \%$ & 17 \\
\hline Elderly's preference & $2.83 \%$ & 18 \\
\hline Cash deposit & $2.82 \%$ & 19 \\
\hline Only son & $2.79 \%$ & 20 \\
\hline Pressure of continuing the family line & $2.58 \%$ & 21 \\
\hline Car and house ownership & $1.97 \%$ & 22 \\
\hline Religious belief & $1.86 \%$ & 23 \\
\hline & $1.47 \%$ & 24 \\
\hline
\end{tabular}




\section{CONCLUSION}

Taiwan has stepped towards the social structure of a low birth rate and an aging population. The low birth rate not only impacts the aspect of education, but also changes the national economic aspect. The work environment of teachers is stable, but is directly affected by the low birth rate. If the number of unmarried teachers continues to increase, the low birth rate will impact itself. This study investigated the key factors affecting mate selection criteria of unmarried female junior high school teachers. The results are summarized, as follows:

I. Hierarchical structure: Four major dimensions were summarized: (1) social condition, (2) personal condition, (3) emotional condition, and (4) family background.

II. Weight: The weights of the four major dimensions are, as follows: (1) emotional condition, (2) personal condition, (3) social condition, and (4) family background. The weights of the secondary assessment criteria under the four primary assessment criteria are, as follows:

(1) Social condition: conviction record (local weight 0.290 , global weight 0.06050 ).

(2) Personal condition: health status (local weight 0.247 , global weight 0.06138 ).

(3) Emotional condition: carefulness and meticulousness (local weight 0.241, global weight 0.08257 ).

(4) Family background: parents are alive and healthy (local weight 0.312 , global weight 0.06351).

\section{REFERENCES}

[1] Yang,L.Y.(2005)“Unmarried Mature and Sophisticated Women- “Three Highs” Women's Future Marriage", Taiwan Panorama, Vol. 2005, pp.88.

[2] Wang, H.C.(2011)“Are You "Unmarried Man” or "Unmarried Woman"? Occupations for Single People”,Cheers Magazine, Vol. 473, pp.123-129.

[3] National Demographic Statistics of All Years: Marriage and Divorce, Available at http://www.ris.gov.tw, Accessed 24 August 2016.

[4] Sakai,J.(2006) Remote Barking of Underdogs, Rye Field Publishing, Taiwan.

[5] Jiang,S.L.(2005)The Effects of the Elementary Unmarried Teachers' Marriage Attitude, Interpersonal Relationship on Mating references, Master's thesis, Graduate Institute of Family Education,National Chiayi University, Taiwan.

[6] Gao, S.G.(1991) Family Sociology, Li Ming Cultural Enterprise, Taiwan.

[7] Tsai, W.H.(2007) Marriage and Family, Wu Nan Books, Taiwan.

[8] Song, C.C.(1997) Sociology, Wu Nan Books, Taiwan.

[9] Ke, R.(2001) Consultation and Psychotherapy: Theories and Practices, YehYeh Book Gallery, Taiwan.

[10] Huang, J.H.(1999) Personality Psychology, Psychological Publishing, Taiwan.

[11] Peng, H.C.(1996) Marriage and Family, Chu Liu Books, Taiwan.

[12] Yi, C.C. andHsung,R.M.(1994)Public Intention of Taiwan's Society: Sociological Analysis, Research Center for Humanities and Social Sciences, Taiwan.

[13] Chang,J.J.(2001)A Study Among Sex-Role, Achievement Motivation and Marriage Attitude of the Elementary Unmarried Teachers, Master's thesis, Graduate Institute of Family Education, National Chiayi University, Taiwan.

[14] Lin, C.P.(2002) A Study on Mate Selection Preference of Unmarried Adolescents, Master's thesis, Graduate Institute of Education, National Chengchi University, Taiwan.

[15] Chang, R.F.(2006) “Influence of Age on Age and Height Preference Thresholds of Mate Selection", Chinese Journal of Psychology, Vol. 48, No. 3, pp.1-15.

[16] Chen, J.Y.(2003) Picking and Choosing - Simulation of Continuous Search of Mate Selection Process, Master's thesis, Graduate Institute of Sociology, National Chengchi University, Taiwan. 
International Journal of Computer Science \& Information Technology (IJCSIT) Vol 9, No 1, February 2017

[17] Hsieh, P.S.(1995) The Marital Attitudes and Life Adjustment of the Unmarried Female Teacher in Junior High School, Master's thesis, Graduate Institute of Human Development \& Family Studies, National Taiwan Normal University, Taiwan.

[18] Cheng, C.Y.and Li, Y.D.(1995), "A Study on Life Perspective, Marriage Perspective, and Social Attitude of College Students",1995 National Academic Conference on Development of College Students Affairs, Taiwan.

[19] Chu, S.H.(2012) A Study of Marriage Willingness of Unmarried Women in Taiwan- Stay Single by Choice or Not?, Master's thesis, Graduate Institute of Social Work, Soochow University, Taiwan.

[20] Lin, C.P.(2002) A Study on Mate Selection Preference of Unmarried Adolescents, Master's thesis, Graduate Institute of Education, National Chengchi University, Taiwan.

[21] Teng, J.Y. Tzeng, G.H.(1989) "Insights, Characteristics, and Application of Analytic Hierarchy Process (I)", Journal of the Chinese Statistical Association, Vol. 27, No. 6, pp.5-27.

[22] Teng, J.Y. Tzeng, G.H.(1989) "Insights, Characteristics, and Application of Analytic Hierarchy Process (II)", Journal of the Chinese Statistical Association, Vol. 27, No. 7, pp. 1-22.

[23] Hou, C.I., Huang, H.C., Tsai, Y.H., Lo, C.Y.(2015), "Research On Decision Making Regarding High-Business-Strategy Café Menu Selection”, International Journal of Computer Science \& Information Technology, Vol. 7, No. 2, pp. 89-97.

[24] Saaty, T.L.(1980) Analytic Hierarchy Process, McGraw-Hill, NY, USA. 